\title{
Teaching Undergraduate Business Students About the Ethicality, Utility, and Risk of Using Personal Social Media Accounts to Vet Candidates in the Employee Recruitment Process
}

\author{
Jay S. Pickern \\ Georgia Highlands College \\ Stacey L. Legler \\ Florida State College at Jacksonville
}

\begin{abstract}
The present study explores the ethicality, utility, and risk of using personal social media accounts to vet candidates in the employee recruitment process. This article details a class lecture and corresponding group activity. The student groups were required to perform a social media deep dive on two individuals viewed as job candidates. Special attention was paid to selection of the correct candidates and information that cannot legally be asked in a job interview. Of the seven student groups, five groups selected incorrect profiles for at least one candidate, while identifying reasons for concern or competitive advantage for each candidate.
\end{abstract}

Keywords: social media, Facebook, Instagram, Twitter, hiring, recruitment

\section{INTRODUCTION}

Social media sites such as Twitter, Facebook, YouTube, Instagram, and similar online outlets present users with a variety of options by which they can share information and connect through mutual interests. However, social media has evolved far beyond making and maintaining personal connections; it also provides a platform for businesses to reach consumers on a global scale. While it is often utilized to advertise products and services, grow larger consumer bases, and engage in other public relations activities, organizations are increasingly turning to social media to recruit and vet job candidates. In fact, a study conducted by the Society for Human Resource Management (2016) reported 84\% of organizations were using social media as a recruiting tool, and $43 \%$ were using a combination of social media sites and online search engines to screen job candidates, a process also known as "cybervetting."

While there is justified debate over the legal and ethical implications of cybervetting, one can easily understand why hiring managers and human resource (HR) professionals engage in this practice. Research has shown that employees - both current and former - have a substantial impact on the reputations of their organizations, and consequently can heavily influence the perceptions of key stakeholders and consumers (Cravens \& Oliver, 2006). The intrinsic characteristics of social media provide employees with the means to voice their unfiltered opinions in real-time, giving them the ability to reach a large audience within seconds. In addition, dissatisfied employees have a growing number of outlets at their fingertips through 
which they can express work-related grievances. Popular social media sites such as Twitter, Facebook, and YouTube often provide the venue for this. However, some sites, such as Glassdoor.com, are specifically designed and marketed to encourage current and former employees to anonymously review their organizations. If negative, this type of exposure can evolve into much more than a simple public relations issue; it might also result in decreased consumer trust, serious and sustained damage to a company's reputation, and in some cases, legal liabilities (Horn et al., 2015). Ultimately, all of this has the potential to negatively impact an organization's competitive advantage, and the risk is multiplied when one considers the viral nature of how quickly information can be disseminated across the internet.

On the other side of this debate are social media users and, for the purposes of this exercise, job seekers. While some might consider personal information that has been voluntarily posted online to be "fair game," others have aptly pointed to the fact that many social media users do not have an adequate understanding of how to manage their privacy settings, and often fail to comprehend the extent to which the information they post online is publicly accessible (Gelinas et al., 2017). This could result in what is known as a "disinhibition effect," in which users present themselves in ways they would consider embarrassing - and would ultimately avoid - if they knew the public (or in this case a potential employer) was watching (Suler, 2004). These are important factors to consider, and they demonstrate the ethical complexities involved in the practice of cybervetting.

Many undergraduate students will enter the job market for the first time upon graduation. Others will be utilizing their degrees and education to further their already established careers. Some will even become hiring managers themselves one day. Given this, it is crucial to recognize the importance of teaching them about the ethicality, utility, and risks involved in using personal social media accounts to vet candidates during the recruiting process.

\section{ETHICALITY}

In general, employers have a legal right to use social media platforms in the recruitment and screening process. While that is true, there are still some questions regarding (1) the fairness of using social media for recruiting and screening, and (2) the applicants' expectations of privacy (Clark \& Roberts, 2010). For the most part, Americans have an expectation of privacy, believing it is a fundamental right. Therefore, job seekers are often under the impression that they have more legal protections than they actually do when it comes to the right of privacy (Davison et al., 2012). Research has shown that applicants are being scrutinized more and more on social media, but only about half of them are even aware of this fact. Additionally, many of these job candidates believe that despite the fact that their profiles are publicly available, they have a right to privacy (Vicknair et al., 2010). According to Davison et al. (2012), the majority of employees think that their personal social media profiles are none of their employers' business.

Some studies have shown that the younger population seems less concerned with privacy when it comes to social media, as opposed to their older counterparts. This does not indicate a lack of concern, but rather points to the fact that this younger generation is not willing to sacrifice their participation on social media in order to separate their professional and personal lives (Sanchez et al., 2012). In fact, Hazelton and Terhorst (2015) found that more job candidates are actually including social media profile information as part of their applications to encourage HR professionals and hiring managers to review their profiles. "Hence, stated expectations of privacy appear to be somewhat inconsistent: employees generally want privacy from unintended employer eyes, and yet they share a significant amount of personal information online, knowing it could become available to employers and others" (McDonald et al., 2016, p. 544).

While employers may have a legal right to use social media in recruitment and screening practices, some ethical dilemmas may arise. There is relevant information that can be obtained through social media, such as professional credentials, work history, and education. On the other hand, there may be information that is irrelevant to the job, but could unduly influence the perception of a candidate without the HR professional or hiring manager realizing it. Hazelton and Terhorst (2015) posited that most of the information on an applicant's social media page may be inconsequential, but there may be information relating to protected class status or other activities not related to the job that could cause problems. 
Ethical dilemmas tend to arise when HR professionals discover questionable or offensive content via social media and must decide what to do with that discovery. Sprague (2011) found that lifestyle concerns are the primary reason candidates are eliminated following a social media screening. Evidence of illegal activities might disqualify a candidate without giving the employer any moral anxiety, but others are not as clear cut. What about disparaging remarks about previous employers, prevalent alcohol use, excessive cursing, rude comments, or extreme political affiliations? While some might consider this behavior offensive or socially inappropriate, is it ethical to disqualify a candidate based on these issues?

As social media platforms have grown in size and popularity, this has created another conundrum. Can the HR professional or hiring manager independently verify the information found on a candidate's public profile? A cursory search for a name on Facebook might return over 100 profiles of different individuals who all have the same name. How does one know one is looking at the correct profile? Additionally, scholars have found that some job candidates have been the victim of identity theft. These job seekers are being scrutinized by employers who have no way of confirming the profile's authenticity, and they likely do not even know the fake profiles exist (Broughton et al., 2010; Hazelton \& Terhorst, 2015).

Even if the authenticity of a candidate's social media profile can be confirmed, the screener runs the risk of fundamental attribution errors. Without the proper context, forming opinions based on negative depictions of a prospective employee on social media might lead to the ill-informed rejection of a qualified candidate. Brown and Vaughn (2011) use the example in which a picture of a woman asleep on a bathroom floor was shown to a conference panel. Some assumed she had consumed too much alcohol. In discussing alternative explanations, the panel discussed the possibility that she might have a medical condition that caused her to fall asleep, or the possibility that it could be a joke between friends. It is impossible to know for sure without the context, and most recruiters do not present candidates with the opportunity to defend themselves (Society for Human Resource Management, 2016). Unfortunately, there is virtually no scholarly guidance at the present time to provide recruiters or hiring managers with best practices or direction in these situations (McFarland \& Ployhart, 2015).

There are some who believe that the use of social media or informal online background checks are an invasion of privacy and harmful to society. According to Segal and LeMay (2014), “....if you wouldn't peek into the applicant's window at home, why look into his or her postings on social media? It's tempting, but not the best ethical choice" (para. 28). Others believe the practice is perfectly ethical, due to the fact that social media gives applicants a place to showcase things that may not be conveyed effectively through the traditional resume or application, such as specific skills or past projects (Hazelton \& Terhorst, 2015; Vicknair et al., 2010).

\section{UTILITY}

According to McFarland and Ployhart (2015), HR functions such as training and development, recruitment, and selection have the potential to be revolutionized by social media. However, the utility of social media as a tool for recruiting purposes depends on its ability to help HR professionals identify abilities, skills, and knowledge of job-related tasks for potential employees. While HR professionals have increased the practice of using social media for recruitment and selection purposes, only two out of five actually believe that looking at a candidate's social media profile can provide information that can reliably predict potential and performance in the workplace (Society for Human Resource Management, 2016).

Social media is typically utilized by HR professionals for screening and recruiting because it takes minimal effort, is cost efficient, and provides fast results (Davison et al., 2012; Jeske \& Shultz, 2016; Slovensky \& Ross, 2012). Because of this, many HR departments are struggling with whether or not to incorporate social media into their recruitment and talent management strategies when the scholarly research to provide them with best practices is virtually nonexistent (McFarland \& Polyhart, 2015). According to McDonald et al. (2016), HR professionals feel that the organization and its shareholders can be protected from negligent hiring by profiling job candidates to ensure they have a clean online presence. In fact, a Deloitte LLP ethics and workplace survey found that $74 \%$ of respondents agreed that an organization's reputation could easily be damaged on social media (Girard \& Fallery, 2010). 
In addition to ensuring a clean online presence, another justification often cited for online profiling is the ability to verify information provided by job seekers (McDonald et al., 2016). According to Maurer (2017), there is a growing trend in falsifications on application documents, cover letters, and resumes. Chauhan et al. (2013) stated that court rulings suggest cybervetting, including the use of social media, is all part of due diligence in determining whether or not job candidates could potentially be a liability for an organization.

While social media might be useful and cost efficient, there are legitimate concerns regarding the credibility of online profile information. Is it really effective to use social media to attract quality candidates? Is social media a legitimate tool to verify job seekers' information? Research has shown that social media users often curate the information posted on profiles to portray themselves in a more flattering light (Davison et al., 2012; Kluemper et al., 2012). "This means applicants' 'regular' behavior may not be captured by such information despite arguments to the contrary, requiring HR managers to assess whether their impressions based on online profile information match offline behaviors or reflect impression management efforts" (Jeske \& Shultz, 2016, p. 539).

According to Kuncel and Tellegen (2009), individuals will often manipulate their online posts based on their intended audiences and what they feel is more socially desirable. For example, a student trying to impress a potential employer might "fake good," or post inaccurate positive information about himself to appear more favorable to employers. On the other hand, a student trying to impress other students might "fake bad," or post inaccurate negative information about himself to imply excessive partying or other behaviors that comply with group norms. Based on these online manipulations, an employer might eliminate the second candidate, not knowing that in reality, that person does not engage in those behaviors. Meanwhile, the first candidate would likely be viewed in a more favorable light (Davison et al., 2012). "Considering HR professionals' admitted use of social media as a tool to assess candidates' personalities, this evidence pointing to misrepresentations of character calls into question its utility for such purposes" (Legler, 2017, p. 27).

\section{RISK}

There are currently no legal regulations or statutes preventing HR professionals and hiring managers from using social media platforms for screening and recruiting purposes (Hazelton \& Terhorst, 2015). In general, communications online are not granted the same protections as their more traditional offline counterparts: “...few protections are afforded to employees or prospective employees who reveal their digital personas online on the basis that they are "publishers in a public realm"” (McDonald et al., 2016, p. 543). The Equal Employment Opportunity Commission (EEOC) has cautioned employers as it relates to using social media in HR. While the use of social media for recruitment and selection is not explicitly permitted or prohibited in anti-discrimination legislation, there could be adverse effects or disparate treatment based on how the information gathered from a social media platform is used (Equal Employment Opportunity Commission, 2014).

\section{IMPLICATIONS (UNCONSCIOUS BIASES)}

"Public profiles allow information that would not be seen on a standard paper application, which causes legal issues to flourish" (Hazelton \& Terhorst, 2015, p. 54). Researching a job seeker's public social media profile may reveal certain demographic factors that are not relevant to future job performance, but provide answers to questions that are illegal to ask on job applications or during interviews, such as race, national origin, marital status, age, religion, sexual orientation, gender, disability status, or whether or not they have children (Jeske \& Schultz, 2016; Thomas et al., 2015). Regardless of a user's privacy settings on social media, the user's profile picture is typically public, which means that a lot of this information could be inferred from the picture alone, even if the profile is set to private (Brown \& Vaughn, 2011).

Research has also shown that, even unintentionally, biases can occur, causing recruiters to target candidates who are similar to themselves. When it comes to selection and recruitment, this could mean an 
HR professional or hiring manager views a candidate more favorably due to something as benign as a common interest, such as a sports team or hobby. These biases become more problematic when candidates are targeted because of similar attributes, such as gender, race, religion, or another sensitive demographic (Roth et al., 2016; Smith \& Kidder, 2010). "Unfortunately, informing us about our biases doesn't seem to help us make better choices. We tend to believe that while others fall prey to such inconsistencies, we ourselves are immune to them" (Bazerman \& Tenbrunsel, 2011, p. 37).

Due to the fact that hiring managers and HR professionals are likely to view a candidate's social media profiles and pictures, it can reasonably be concluded that some type of discriminatory bias has the potential to occur during this stage in the recruitment process, as skin tone and name are readily apparent (Derous et al., 2017; Van Iddekinge et al., 2013).

According to Chauhan et al. (2013), HR professionals argue that their opinions in the recruiting and selection process are not biased by information regarding an applicant's membership in a protected class, and the discovery of that membership via social media will have no disparate impact on the process. Jeske $\&$ Schultz (2016) shine the light of skepticism on this line of thinking:

...it is somewhat questionable to what degree HR managers can effectively forget and disregard information about an applicant's ethnicity and race, gender, health, undisclosed disabilities, sexual orientation and other highly sensitive information often available on an applicant's social media profile. (p. 540)

\section{ASSIGNMENT}

After a lecture and class discussion on the ethicality, utility, and risk of using social media in the recruitment process, the students were assigned a project to reiterate the principles covered in class. In this particular class, the students had already been pre-assigned into groups. Each group was given the names of two individuals to view as job candidates. The groups were to act as HR managers doing a social media deep dive (Facebook, Twitter, Instagram, and YouTube) on the candidates to see what information they could find. Each group had to present their candidates to the class along with all of the information they were able to find from public and private profiles (including whether or not they had identified the correct social media profiles of the candidates). The groups had to explain whether or not they saw anything that would cause them to not hire a candidate, or whether or not they saw something that would give the candidate a competitive advantage. Special attention was paid to information that can be found on social media, but cannot legally be asked in the interview process (marital status, race, children, sexual orientation, political affiliations, religious beliefs, etc.).

TABLE 1

ASSIGNMENT RESULTS

\begin{tabular}{rlrc}
\hline Group & \multicolumn{1}{c}{ Candidate \#1 } & Candidate \#2 \\
\hline \multirow{2}{*}{$\begin{array}{l}\text { Correct Identification of } \\
\text { Candidate }\end{array}$} & $\begin{array}{l}\text { Reasons for Concern or to } \\
\text { Disqualify Candidate }\end{array}$ & $\begin{array}{l}\text { Concerning profile pictures, use } \\
\text { of N-word, cartoon depiction of } \\
\text { gang activity and drug use }\end{array}$ & $\begin{array}{c}\text { Pictures with \#drunk, several } \\
\text { political posts with } \\
\text { \#hatedonaldtrump }\end{array}$ \\
\cline { 2 - 4 } & $\begin{array}{l}\text { Competitive Advantage to } \\
\text { Candidate }\end{array}$ & Claims to be OSHA Certified \\
2 & $\begin{array}{l}\text { Correct Identification of } \\
\text { Candidate }\end{array}$ & $\begin{array}{c}\text { Friendly disposition, fights } \\
\text { for equal rights }\end{array}$ \\
\hline $\begin{array}{l}\text { Reasons for Concern or to } \\
\text { Disqualify Candidate }\end{array}$ & Yes & No \\
\hline
\end{tabular}




\begin{tabular}{|c|c|c|c|}
\hline Group & & Candidate \#1 & Candidate \#2 \\
\hline & $\begin{array}{l}\text { Competitive Advantage to } \\
\text { Candidate }\end{array}$ & $\begin{array}{l}\text { Positive attitude, college } \\
\text { educated, stable personal life }\end{array}$ & $\begin{array}{l}\text { Seems to be a well-rounded } \\
\text { individual, lives a happy life }\end{array}$ \\
\hline \multirow{3}{*}{3} & $\begin{array}{l}\text { Correct Identification of } \\
\text { Candidate }\end{array}$ & Yes & Yes \\
\hline & $\begin{array}{l}\text { Reasons for Concern or to } \\
\text { Disqualify Candidate }\end{array}$ & $\begin{array}{l}\text { Seems a bit wild, multiple } \\
\text { pictures flipping the bird, no job } \\
\text { experience longer than one year }\end{array}$ & $\begin{array}{c}\text { A few political posts on } \\
\text { Twitter account, but nothing } \\
\text { outrageous }\end{array}$ \\
\hline & $\begin{array}{l}\text { Competitive Advantage to } \\
\text { Candidate }\end{array}$ & Seems energetic & $\begin{array}{l}\text { Loyal employee with stable } \\
\text { job history and longevity } \\
\text { with her current organization }\end{array}$ \\
\hline \multirow{3}{*}{4} & $\begin{array}{l}\text { Correct Identification of } \\
\text { Candidate }\end{array}$ & Yes & Yes \\
\hline & $\begin{array}{l}\text { Reasons for Concern or to } \\
\text { Disqualify Candidate }\end{array}$ & $\begin{array}{l}\text { Strong political views on social } \\
\text { media, covered in tattoos } \\
\text { (including face and neck) }\end{array}$ & $\begin{array}{l}\text { Pregnant, travels a lot and } \\
\text { will want time off, some } \\
\text { moderate to strong political } \\
\text { leanings }\end{array}$ \\
\hline & $\begin{array}{l}\text { Competitive Advantage to } \\
\text { Candidate }\end{array}$ & $\begin{array}{c}\text { Talented artist, web design } \\
\text { experience, computer support } \\
\text { experience, small business } \\
\text { owner }\end{array}$ & $\begin{array}{l}\text { Spiritual, goal oriented, } \\
\text { positive attitude }\end{array}$ \\
\hline \multirow{3}{*}{5} & $\begin{array}{l}\text { Correct Identification of } \\
\text { Candidate }\end{array}$ & No & Yes \\
\hline & $\begin{array}{l}\text { Reasons for Concern or to } \\
\text { Disqualify Candidate }\end{array}$ & $\begin{array}{l}\text { Scheduling concerns due to } \\
\text { recently being married with two } \\
\text { children }\end{array}$ & $\begin{array}{c}\text { Recently married and likely } \\
\text { to be starting a family soon } \\
\text { as indicated by post about a } \\
\text { miscarriage }\end{array}$ \\
\hline & $\begin{array}{l}\text { Competitive Advantage to } \\
\text { Candidate }\end{array}$ & $\begin{array}{l}\text { Seems responsible and } \\
\text { professional }\end{array}$ & $\begin{array}{c}\text { Seems to be stable and } \\
\text { hardworking }\end{array}$ \\
\hline \multirow{3}{*}{6} & $\begin{array}{l}\text { Correct Identification of } \\
\text { Candidate }\end{array}$ & 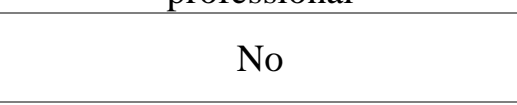 & Tom \\
\hline & $\begin{array}{l}\text { Reasons for Concern or to } \\
\text { Disqualify Candidate }\end{array}$ & N/A & N/A \\
\hline & $\begin{array}{l}\text { Competitive Advantage to } \\
\text { Candidate }\end{array}$ & $\begin{array}{l}\text { No political posts, family } \\
\text { oriented and athletic (team } \\
\text { player) }\end{array}$ & $\begin{array}{l}\text { Family oriented, recently } \\
\text { married (stability) }\end{array}$ \\
\hline \multirow{3}{*}{7} & $\begin{array}{l}\text { Correct Identification of } \\
\text { Candidate }\end{array}$ & Yes & No \\
\hline & $\begin{array}{l}\text { Reasons for Concern or to } \\
\text { Disqualify Candidate }\end{array}$ & $\begin{array}{l}\text { Questionable taste in attire, } \\
\text { some political posts }\end{array}$ & $\begin{array}{l}\text { Some pictures of social } \\
\text { drinking }\end{array}$ \\
\hline & $\begin{array}{l}\text { Competitive Advantage to } \\
\text { Candidate }\end{array}$ & $\begin{array}{c}\text { Enthusiastic, successful real } \\
\text { estate business }\end{array}$ & Social, family oriented \\
\hline
\end{tabular}

Upon completion of the group presentations, students were made aware of whether or not their groups chose and evaluated the correct profiles of the candidates. After all groups had presented, the class discussed the fact that several groups found information that could not be legally asked in an interview, even from profiles that were set to private. The class also discussed the fact that several groups made judgements about potential candidates based on the wrong social media profiles. 


\section{CONCLUSION}

Given what is known about the increasing use and prevalence of social media in everyday life, it is important to evaluate the ethicality, utility, and risk involved in its use for targeted purposes, such as job recruitment and selection. Regardless of the questions and concerns surrounding it, the reality is that cybervetting is utilized by an ever-growing number of hiring managers and HR professionals alike, and this is not likely to change. Therefore, it is imperative that we educate undergraduate students - who will soon be job seekers, and possibly hiring managers themselves one day - on this topic. It is, however, crucial to incorporate the perspectives of both those engaging in cybervetting, and those who are the subject of it, in order to equip students with the knowledge needed to make informed decisions regarding what might help or hinder them during the job search process. This exercise is designed to be a key component of that education, and the nature of its practical application is likely to have a lasting impact on the students who participate.

\section{REFERENCES}

Bazerman, M.H., \& Tenbrunsel, A.E. (2011). Blind spots: Why we fail to do what's right and what to do about it. Princeton, NJ: Princeton University Press.

Broughton, A., Higgins, T., Hicks, B., \& Cox, A. (2010). Workplaces and social networking: The implications for employment relations. Retrieved from http://www.acas.org.uk/media/pef/f/q/1111_Workplaces_and_Social_Networking-accessibleversion-Apr-2012.pdf

Brown, V.R., \& Vaughn, E.D. (2011). The writing on the (Facebook) wall: The use of social networking sites in hiring decisions. Journal of Business and Psychology, 26(2), 219-225.

Chauhan, R.S., Buckley, M.R., \& Harvey, M.G. (2013). Facebook and personnel selection: What's the big deal? Organizational Dynamics, 42(2), 126-134.

Clark, L.A., \& Roberts, S.J. (2010). Employer's use of social networking sites: A socially irresponsible practice. Journal of Business Ethics, 95, 507-525.

Cravens, K.S., \& Oliver, E.G. (2006). Employees: The key link to corporate reputation management. Business Horizons, 49(4), 293-302. doi:10.1016/j.bushor.2005.10.006

Davison, H.K., Maraist, C., Hamilton, R.H., \& Bing, M.N. (2012). To screen or not to screen? Using the Internet for selection decisions. Employee Responsibilities and Rights Journal, 24, 1-21.

Derous, E., Pepermans, R., \& Ryan, A.M. (2017). Ethnic discrimination during resume screening: Interactive effects of applicants' ethnic salience with job context. Human Relations, 70(7), 860882.

Equal Employment Opportunity Commission. (2014). Social media is part of today's workplace but its use may raise employment discrimination concerns [Press release]. Retrieved from https://www.eeoc.gov/eeoc/newsroom/release/3-12-14.cfm

Gelinas, L., Pierce, R., Winkler, S., Cohen, I.G., Lynch, H.F., \& Bierer, B.E. (2017). Using social media as a research recruitment tool: Ethical issues and recommendations. The American Journal of Bioethics, 17(3), 3-14. doi:10.1080/15265161.2016.1276644

Girard, A., \& Fallery, B. (2010). Human resource management on the Internet: New perspectives. Journal of Contemporary Management Research, 4(2), 1-14.

Hazelton, A.S., \& Terhorst, A. (2015). Legal and ethical considerations for social media hiring practices in the workplace. The Hilltop Review - Western Michigan University, 7(2), 53-59.

Horn, I.S., Taros, T., Dirkes, S., Hüer, L., Rose, M., Tietmeyer, R., \& Constantinides, E. (2015). Business reputation and social media: A primer on threats and responses. Journal of Direct, Data and Digital Marketing Practice, 16(3), 193-208. doi:10.1057/dddmp.2015.1

Jeske, D., \& Shultz, K.S. (2016). Using social media content for screening in recruitment and selection: Pros and Cons. Work, Employment and Society, 30(3), 535-546. 
Kluemper, D.H., Rosen, P., \& Mossholder, K. (2012). Social networking websites, personality ratings, and the organizational context: More than meets the eye? Journal of Applied Social Psychology, $42,1143-1172$.

Kuncel, N.R., \& Tellegen, A. (2009). A conceptual and empirical reexamination of the measurement of the social desirability of items: Implications for detecting desirable response style and scale development. Personnel Psychology, 62, 201-228.

Legler, S.L. (2017). The use of social media for recruitment and selection: Exploring HR professionals' perceptions of utility, ethicality, and risk. (Doctoral Dissertation). Retrieved from ProQuest (10742864).

Maurer, R. (2017, April 28). Past employment checks are critical to the hiring process. Society for Human Resource Management. Retrieved from https://www.shrm.org/resourcesandtools/hr-topics/talentacquisition/pages/past-emplomnet-checks-hiring-process.aspx

McDonald, P., Thompson, P., \& O'Connor, P. (2016). Profiling employees online: Shifting public-private boundaries in organizsational life. Human Resource Management Journal, 26(4), 541-556.

McFarland, L.A., \& Ployhart, R.E. (2015). Social media: A contextual framework to guide research and practice. Journal of Applied Psychology, 100(6), 1653-1677.

Parsi, K., \& Elster, N. (2014). Conducting research on social media - is Facebook like the public square? The American Journal of Bioethics, 14(10), 63-65. doi:10.1080/15265161.2014.947825

Roth, P.L., Bobko, P., Van Iddekinge, C.H., \& Thatcher, J.B. (2016). Social media in employee-selectionrelated decisions: A research agenda for uncharted territory. Journal of Management, 42(1), 269298.

Sanchez Abril, P., Levin, A., \& Del Riego, A. (2012). Blurred boundaries: Social media privacy and the twenty-first century employee. American Business Law Journal, 49(1), 63-124.

Segal, J.A., \& LeMay, J. (2014, November 1). Point/counterpoint: Should employers use social media to screen job applicants? Society for Human Resource Management. Retrieved from https://www.shrm.org/hr-today/news/hr-magazine/pages/1114-social-media-screening.aspx

Slovensky, R., \& Ross, W.H. (2012). Should human resource managers use social media to screen job applicants? Managerial and legal issues in the USA. Info, 14, 55-69.

Smith, W.P., \& Kidder, D.L. (2010). You've been tagged! (Then again, maybe not): Employers and Facebook. Business Horizons, 53(5), 491-499.

Society for Human Resource Management. (2016). SHRM survey findings: Using social media for talent acquisition [PDF document]. Retrieved from https://www.shrm.org/hr-today/trends-andforecasting/research-andsurveys/Documents/SHRM-Social-Media-Recruiting-Screening2015.pdf

Sprague, R. (2011). Invasion of the social networks: Blurring the line between personal life and the employment relationship. University of Louisville Law Review, 50(1), 1-34.

Suler, J. (2004). The online disinhibition effect. CyberPsychology \& Behavior, 7(3), 321-326. doi:10.1089/1094931041291295

Taddicken, M. (2013). The 'privacy paradox' in the social web: The impact of privacy concerns, individual characteristics, and the perceived social relevance on different forms of self-disclosure. Journal of Computer-Mediated Communication, 19(2), 248-273. doi:10.1111/jcc4.12052

Thomas, S., Rothschild, P., \& Donegan, C. (2015). Social networking, management responsibilities, and employee rights: The evolving role of social networking in employment decisions. Employee Responsibilities \& Rights Journal, 27(4), 307-323.

Van Iddekinge, C.H., Lanivich, S.E., Roth, P.L., \& Junco, E. (2013). Social media for selection? Validity and adverse impact potential of a Facebook-based assessment. Journal of Management, 42(7), 1811-1835.

Vicknair, J., Elkersh, D., Yancey, K., \& Budden, M. (2010). The use of social networking sites as a recruiting tool for employers. American Journal of Business Education, 3(11), 7-12. 